\title{
El perfil de las elites pecheras en los concejos bajomedievales: prácticas y trayectorias. Piedrahíta en el siglo XV
}

The profile of the elites pecheras in the late medieval councils: practices and trajectories. Piedrahita in the Fifteenth
Century.

Rocio Bello Gay

Facultad de Filosofía y Letras, Universidad de Buenos Aires-CONICET,

Argentina

rociobellogay@gmail.com

\section{Resumen:}

El estudio de la documentación concejil de Piedrahíta da cuenta de la creciente consolidación de miembros provenientes del estamento pechero que a lo largo del siglo XV ocupan cargos políticos y de gestión tanto a nivel urbano como a nivel rural, al mismo tiempo que desarrollan procesos de acumulación de distinto tipo. El seguimiento de algunas de las figuras destacadas de los no privilegiados permite aportar a la caracterización de las prácticas, estrategias y trayectorias de dichos sectores en los siglos bajomedievales. Palabras claves: elites pecheras-prácticas-trayectorias- Piedrahíta-Siglo XV Title: The profile of the elites pecheras in the late medieval councils: practices and trajectories. Piedrahíta in the Fifteenth Century.

Palabras clave: Elites pecheras, Prácticas, Trayectorias, Piedrahíta, Siglo XV.

\section{Abstract:}

The aim of this article is to deepen the understanding of the elites pecheras in Piedrahíta council. Through the fifteenth century members from the unprivileged estate consolidate their position occupying political positions and local offices at both urban and rural levels, at the same time as the devolpdifferent types of accumulation processes. The analysis of some of these outstanding figures contributes to the characterization of their practices, strategies and trajectories in the late medieval centuries.

KeYwords: Elites pecheras, Practices, Trajectories, Piedrahita, Fifteenth century.

\section{INTRODUCCIÓN}

En las últimas décadas la historiografía castellana ha puesto de relieve la diferenciación social que atraviesan las comunidades tributarias en los siglos bajomedievales. Diversos autores dedicados a la historia social revisan la extendida imagen de comunidades rurales homogéneas y ponderan la existencia de procesos de acumulación de sectores provenientes del estamento pechero. En este sentido, a partir de la década del '80 diversos hispanistas recuperan los aportes centrales de la escuela marxista británica, que en el marco del debate de la transición del feudalismo al capitalismo, enfatiza los procesos de acumulación económica de un sector superior en las aldeas, protagonista de las transformaciones del campo inglés en los últimos siglos de la Edad Media y primeros siglos de la Edad Moderna.

La perspectiva de esta escuela, con Maurice Dobb (1975; 1982) y Rodney Hilton (1974; 1975; 1982; 1988) como máximos exponentes, se presenta como clara heredera de los estudios de Lenin (1957) de finales del siglo XIX, quien pone el foco en el papel de los mecanismos económicos de la diferenciación social y la consecuente descomposición de las comunidades en el surgimiento del capitalismo en Rusia. Reconoce Lenin la división del campesinado en dos clases: por un lado, el polo superior de las comunidades al que caracteriza como una burguesía agraria, que posee tierras de mayores dimensiones, comercializa su producción, contrata 
mano de obra asalariada y realiza reinversiones productivas; y el inferior, compuesto por una mayoría de campesinos pobres que vende su fuerza de trabajo, a pesar de conservar una pequeña porción de tierra.

Desde esta línea interpretativa, la mayoría de los historiadores marxistas que participan del debate inicial de la transición postulan el surgimiento de relaciones capitalistas en el marco de la pequeña producción campesina y al estrato superior del campesinado como el principal agente de la transformación de las relaciones de propiedad al experimentar un proceso de acumulación económico de nuevo tipo. En esta dirección, describen las distintas actividades y estrategias de acumulación puestas en práctica por un "tipo distinto de ricos" surgido al interior del campesinado (Hilton, 1988: 134), cuyas formas de explotación anticipan la agricultura capitalista, destinando la mayor parte de su excedente a la venta y ampliando la extensión de sus parcelas (Dyer, 1984, 1998).

El camino trazado por esta escuela será sumamente influyente entre los hispanistas; numerosos autores dedicados a la historia agraria, a partir de estudios de carácter local, comprueban para el área castellana la existencia de procesos de acumulación en el marco de las aldeas castellanas y describen las actividades productivas de los sectores no privilegiados provenientes del medio rural. (Asenjo González, 1984; Oliva Herrer, 2008; Borrero Fernández, 2015, 2008; Sánchez Benito, 2008; Clemente Ramos, 2011, 2004; Astarita, 2005). No obstante la riqueza de dichos aportes, entendemos que en cierta medida el influjo de la narrativa británica y su interés en la génesis de relaciones capitalistas ha llevado a la construcción de modelos dualistas que identifican de manera unilineal los procesos de acumulación con la emergencia de relaciones de nuevo tipo.

Asimismo, observamos que entre los trabajos del área concejil castellana persiste una separación entre los análisis dedicados a las formas de organización y participación política de los no privilegiados -tanto urbanos como rurales (Monsalvo Antón, 1989, 2011b, 2004, Diago Hernando, 1990; Jara Fuente, 2002; 2002-2003)y los estudios de corte económico que en las dos últimas décadas parecen haber perdido terreno en la agenda historiografía.

Estas últimas falencias pretenden ser resueltas por los recientes trabajos sustentados en clave de la sociología de las elites, los cuales se presentan como una superación de las "estrecheces" o "constricciones" de los análisis clásicos. Las nuevas variables, como el prestigio entre sus pares, la influencia en las respectivas comunidades y los atributos políticos, configuran aspectos fundamentales de los nuevos planteos historiográficos. En el marco de la revitalización general en todo el espacio europeo de la categoría de "elites rurales" y en el caso español de la noción de las "elites pecheras", se busca dar cuenta de la amplitud y heterogeneidad de los sectores superiores comunitarios que se destacan por su situación económica, pero también por su posición política o de reconocimiento social (Domínguez de la Concha, 2016; Aparisi Romero, 2013; Guinot Rodríguez, 2010; Menant y Jessenne, 2007; Feller, 2015, 2003).

Sin embargo, la adopción de dicha categoría no ha significado necesariamente un avance en el conocimiento del tipo de prácticas de estas minorías. En particular, se ha abandonado la preocupación por comprender el carácter de la acumulación desarrollada por estos grupos, así como se ha tendido a englobar de manera indiferenciada a todos los sectores que gozan de alguna cuota de preeminencia comunitaria. En el presente artículo, a partir del análisis empírico de un concejo particular, nos proponemos aportar a la caracterización del tipo de acumulación llevada adelante por los sectores pecheros, considerando la incidencia en estos desarrollos del acceso a las instancias de gestión política.

\section{Piedrahíta en el Siglo XV}

El presente estudio se concentra en el seguimiento de algunos sectores prominentes de los pecheros de la comunidad de villa y tierra del concejo de Piedrahíta durante el siglo XV. Para ello es necesario precisar algunas de las características de dicho concejo. Perteneciente al alfoz de Ávila, esta villa es separada del espacio de realengo para formar -junto con las villas de El Barco, El Mirón, La Horcajada y Bohoyo- el señorío de 
Valdecorneja. Aunque no es objeto de tratamiento aquí, la villa de Piedrahíta es sometida a una serie de vaivenes jurisdiccionales, ${ }^{1}$ pero ya para el siglo XV, ha sido otorgada al poderoso linaje nobiliario de los Álvarez de Toledo. (Luis López, 1987; Moreno Núñez, 2007, 1992; Calderón Ortega, 2005, 1994).

Al igual que la mayoría de los concejos extremeños, el concejo de Piedrahita atraviesa en los siglos bajomedievales un proceso de cierre mediante el cual los cargos de gobierno, administración y justicia del concejo quedan en manos de una minoría de privilegiados proveniente de los caballeros. Aún cuando se encuentra mediatizado por la presencia señorial que incide en las designaciones e impone oficiales tales como el alcalde mayor, la minoría dirigente controla el ejercicio efectivo de los principales cargos concejiles. En este sentido, su organización política no sufre modificaciones sustanciales pese a la señorialización. ${ }^{2}$

El tamaño relativamente reducido del concejo incide en las características de su elite dirigente que, ${ }^{3}$ por un lado, tiene una intensa participación en el gobierno de la villa, y por otro, se involucra de manera activa en procedimientos administrativos y en la ejecución de las medidas del ayuntamiento (Luchía, 2019). ${ }^{4}$ Del mismo modo, la dimensión limitada de la comunidad es un factor que influye en la importante presencia pechera en la gestión local. En este sentido, pese a su carácter señorializado, Piedrahíta no constituye una excepción en relación a la capacidad de participación de los pecheros de la villa y tierra castellanos, aún cuando estos se encuentran excluidos de las instancias superiores del poder municipal. (Monsalvo Antón, 1989, 2011b, 2004, Diago Hernando, 1990; Jara Fuente, 2002; 2002-2003). ${ }^{5}$

A lo largo de la documentación concejil se observa una intensa intervención de los pecheros principalmente en las cuestiones ligadas a la fiscalidad. Prácticamente en la totalidad de los registros de repartimientos de distinta índole- correspondientes a las obligaciones regias y señoriales- se verifica la presencia de sectores tributarios. Hasta mediados del siglo XV, la referencia documental a la asistencia de representantes pecheros al ayuntamiento señala un menor grado de institucionalización, de allí las fórmulas genéricas con que se los registra. Cuando las autoridades concejiles se reúnen para tasar y derramar los pechos, se encuentran presentes "otros omnes buenos pecheros de la villa e de la tierra", "pieca de los pecheros de la villa e de la tierra", "ciertos pecheros de la dicha villa e quartos e de la tierra", "vezinos y moradores de los logares de la dicha villa e su término". (Luis López, 2007)

No obstante, el procurador del concejo, quien ejerce la máxima representación del colectivo, se destaca por su protagonismo de manera temprana. Desde inicios del siglo, en 1406, encontramos documentada su asistencia a las reuniones del concejo en las cuales, al igual que en toda el área castellana, tenía voz pero no voto. Elegidos anualmente por el común, quienes ocupan dicho cargo pertenecen al estado de los contribuyentes siendo personas "llanadas, abonadas de buena familia y conciencia" . ${ }^{6}$ A diferencia de los demás oficios pecheros, se lo menciona de manera diferenciada a lo largo de todo el siglo XV no solamente en los registros de repartimientos sino también en las distintas disposiciones o transacciones que realiza el concejo.

El cargo de procurador es recompensado con 300 maravedís de salario, equivalente al que reciben los regidores y mayordomos, a lo que se adicionan sumas de dinero por el cumplimiento de ciertas obligaciones específicas como las visitaciones a los sexmos o salidas fuera de la tierra. Esto puede observarse en los libros de gastos del concejo. Tomemos como ejemplo a Juan Alonso de Úbeda quien cumple esta tarea política en 1460. El concejo le paga su salario (Monsalvo Antón, 2011a: 185; Del Ser Quijano, 2010, 169: 170), pero también diversas cantidades de maravedíes por tareas que realiza para el concejo, como ir con los alcaldes y regidores a ver el agua del río que atajaban los de la aldea de Navahermosa impidiendo que llegara a la villa, tomar medidas de la Sierra de la Gata y elaborar una escritura del concejo (Monsalvo Antón, 2011a: 192; 200; 202). Si bien estas cuantías no representan sumas elevadas, desempañarse como procurador trae asociados otros beneficios. Por un lado, gozan de algunas exenciones, desde julio de 1464 se los exime -junto con el mayordomo y escribano "por ser oficiales del dicho concejo"- de acoger huéspedes en su casa cuando el señor de Valdecorneja visita la villa y de que se les tomara ropa de sus casas (Luis López, 2012, 89: 135). 
Por otro lado, el principal atractivo del cargo se encuentra ligado a los contactos que el mismo ofrece. La procuraduría del concejo parece transformarse en uno de los escalones obligados de las familias pecheras con proyecciones sociales en la villa. La participación en el remate de bienes de propios y el arriendo de rentas concejiles forma parte de las actividades más rentables de muchas de estas figuras. Sigamos con Alonso de Úbeda. El primer registro en este sentido es de 1458 cuando Juan González el Viejo le traspasa la mitad de la renta del peso del concejo que le había sido rematada en pública subasta (Del Ser Quijano, 2010, 124: 255). En los años siguientes remata la carnicería junto con don Salomón Cohen (Luis López, 2012, 4: 37), puja por la renta del peso del concejo y recibe 100 maravedís por la alcabala del pescado fresco que se vende en la villa (Monsalvo Antón, 2011a: 219; 196). ${ }^{7}$ Como veremos, su trayectoria no es excepcional.

Asimismo, el análisis de la documentación refleja que pese a la duración anual del cargo, los nombres de sus ocupantes se repiten a lo largo del siglo XV. Del mismo modo que dentro de la elite privilegiada de la villa prima la consolidación de familias dirigentes, dentro del común se verifica la aparición no solamente de individuos destacados sino también de sus parientes cercanos que acceden a cargos políticos relevantes. Esta lógica familiar es un posible indicio de la conformación de linajes pecheros con cuotas significativas de poder en la comunidad. El seguimiento de estas figuras en los registros concejiles nos permite establecer un primer perfil de los sectores prominentes de los tributarios.

Los Fernández de los Caños, familia cuyos miembros se destacan a lo largo de todo el siglo XV, constituyen un ejemplo paradigmático en este sentido. En 1426, Alfonso Fernández de los Caños es mencionado como cogedor del servicio de los señores por el cuarto de Cavalleruelos y en la década siguiente como procurador del concejo en años sucesivos -1435, 1436, 1437 y 1439-participando de las reuniones del ayuntamiento en transacciones sobre tierras, reparto de pechos y actuando como testigo de disposiciones concejiles (Calleja Puerta, 2010: 201, 202; Luis López, 2007: 46, 49, 50, 66, 125).

No obstante, la destacada posición de los Fernández de los Caños se consolida hacia la mitad de la centuria cuando Diego Fernández de los Caños y su hermano Alonso alcanzan posiciones centrales en el concejo de la villa. ${ }^{8}$ El primero se desempeña como mayordomo del concejo en 1450 (Luis López, 2011: 169, 174, 178; Del Ser Quijano, 2010, 13: 65). La elección de los candidatos a la mayordomía en Piedrahíta recae en la justicia, regidores y procurador del concejo y cuenta con la aprobación del señor, lo que evidencia que aquellos que ocupan este puesto deben gozar tanto de conexiones con la elite dirigente como de la voluntad señorial. Si bien ha sido señalado que se trata de un puesto menor en relación a los principales oficios concejiles, ${ }^{9}$ el mayordomo, que actúa a su vez como tesorero, maneja importantes recursos líquidos. Aunque era supervisado por las demás autoridades de la villa, tiene a su cargo todos los ingresos de rentas, propios y penas del concejo, lo que podría habilitar oportunidades de enriquecimiento. (Luis López, 1987: 280-281). Por su parte, Alonso Fernández de los Caños ocupa la procuraduría en 1456 y 1457 y representa a los pecheros en la toma de cuentas al mayordomo en 1458. (Monsalvo Antón, 2011a: 77, 111, 118; Del Ser Quijano, 2010: 112, 113, $114,118,120)$.

La posición destacada de la familia en la dinámica política de la villa se corresponde con una activo involucramiento en transacciones comerciales con el concejo. Entre 1447 y 1460, Diego Fernández de los Caños recibe en varias oportunidades ciertas sumas de dinero por carreteadas de piedra y cal para diversas obras del concejo, por el riego de las pasturas (Luis López, 2011: 149, 200, 228; Monsalvo Antón, 2011a: $46,47,143,147,148,149,162,186,187,191,200,203)$ y mil maravedís por "cierto alcance que él fizo al concejo desta villa el año que el fue mayordomo" (Luis López, 2011: 252). ${ }^{10}$

Hacia finales de la década de 1460, los Fernández de los Caños consolidan su relevancia política. Aunque no podemos establecer con certeza que se trate de los mismos personajes, de manera indudable estamos frente a individuos de la misma familia: Alonso Fernández de los Caños se desempeña como mayordomo de la villa en 1467 (Del Ser Quijano, 2016,26,31,33; Beltrán Suárez, 2011:37), mismo año en que el concejo se ayunta en su propia casa lo que marca su rol prominente en la comunidad (Del Ser Quijano, 2016, 15); en tanto que Diego Fernández de los Caños es procurador en 1474 y actúa como testigo en 1476 (Del Ser Quijano, 
2016, 75, 79, 81, 93; Álvarez Fernández, 2011, 34, 35, 55). Es necesario destacar que más allá del acceso a los oficios urbanos, ambos son mencionados como labradores lo que da cuenta de su condición rural (Beltrán Suárez, 2011: 127). ${ }^{11}$

Los Sánchez Sastre son otro ejemplo emblemático del protagonismo de cierta fracción de los no privilegiados en la dinámica concejil, tanto por su desempeño público como por la destacada participación en el arriendo de rentas y bienes de propios del concejo. Al igual que los Fernández de los Caños, representan a los pecheros y ocupan la procuraduría y mayordomía de la villa en distintas oportunidades desde fines de la década de 1440. Pedro Sánchez Sastre es mayordomo del concejo en 1449, actúa en nombre de sus pares en la toma de cuenta al mayordomo en 1462, es procurador en 1466 y oficia como testigo en diversas ocasiones (Del Ser Quijano, 2010, 8, 112, 129; Monsalvo Antón, 2011a: 216, 217, 218; Tena García, 2011: 58, 64). Por su parte, su hijo Diego Sánchez Sastre también participa en 1458 en la toma de cuenta al mayordomo Lope García y ejerce como procurador del concejo en 1461, 1466, 1469, 1470 y en 1471. (Monsalvo Antón, 2011a: 2, 3, 64, 118, 214; Del Ser Quijano, 2016, 56; Beltrán Suárez, 2011: 87, 96, 98, 109, 110, 114,116, $130,138,143)$. Su relevancia política también conlleva su intensa actuación como testigo de las distintas disposiciones concejiles (Monsalvo Antón, 2011a: 65, 67, 77, 220, 221, 225).

Como hemos señalado, la implicancia política de ambos es acompañada por su intervención constante en el arriendo de rentas concejiles. Ya en 1452, Pedro Sánchez Sastre arrienda la renta del pan con Lope García y con Samuel Pinto y la renta del peso con Abraham Cohen (Del Ser Quijano, 2010, 2, 41). Unos años más tarde, en 1457, 1459 y 1462 se repite el arriendo de la renta del peso nuevamente con Lope García, por un valor de 9 mil, 13 mil y 15.400 maravedís respectivamente (Del Ser Quijano, 2010, 163; Tena García, 2011: 65). En 1462 arrienda también las rentas de las penas y en 1464, con otros vecinos, la renta de la cerca en 25 , 200 maravedís (Luis López, 2012, 43; Tena García, 2011: 131, 132). Su consolidada situación patrimonial le permite asimismo actuar en 1459 como fiador de su hijo Diego cuando se comprometen a pagar al concejo 21.000 maravedís por la renta del cornado (Del Ser Quijano, 2010, 144).

Pese a su residencia urbana y al vínculo de su apellido con la actividad artesanal, los Sánchez Sastre desarrollan tareas rurales cuya producción comercializan con el concejo de Piedrahíta; en 1460 Diego Sánchez recibe 150 maravedís del mayordomo del concejo por "seis cántaros de vino de su cogecha” (Monsalvo Antón, 2011a: 192). Asimismo, participa del remate de propios del concejos: en 1466 "rremató la dicha defesa en Diego Sánchez, sastre, en esta manera: la vaca o novillo que pague a cinco blancas e la cabra a media et el puerco a blanca e el cochino a media blanca" (Monsalvo Antón, 2011a: 219). ${ }^{12}$

La relevancia de Diego Sánchez Sastre se fortalece a partir de su relación estrecha con Alonso de Vergas, cabeza de uno de los linajes principales de los privilegiados de la villa quien en 1488 lo presenta como testigo en el pleito que mantiene por las alcacerías con el duque de Alba (Luis López, 2016, 37, 42). ${ }^{13}$ Todos los individuos presentados por Alonso de Vergas en esta oportunidad son pecheros. Este vínculo resulta sugerente; es posible que las trayectorias ascendentes de algunos sectores de los tributarios se consoliden a partir de los lazos que mantienen con la elite dirigente local. Sin embargo, esta relación no se encuentra exenta de conflictividad y rivalidades.

En 1464 el regidor García de Vergas y el alcalde Martín Ferrández de Pineda en nombre de las autoridades concejiles se quejan ante el conde de Alba que los fielazgos "que solían ser dados a los más honrrados de la dicha villa" ahora "andan abatydos en personas comunes" (Luis López, 2012, 83: 125-126). ${ }^{14} \mathrm{El}$ ascenso de un sector enriquecido del común que accede a cargos concejiles, mantiene vínculos con sectores poderosos y desarrolla una acumulación patrimonial ligada a la reproducción de las relaciones de explotación feudal, puede presentarse también como una amenaza para la minoría privilegiada de Piedrahíta (Luchía, 2019). 


\section{La tierra de Piedrahíta}

En este segundo apartado nos concentraremos en los sectores ascendentes de la tierra de Piedrahíta ${ }^{15}$ Hemos señalado que hasta mediados del siglo, la mención a los oficiales pecheros es limitada y se ciñe a la presentación de fórmulas genéricas. En estas primeras décadas, la participación más destacada de los pecheros de la tierra es la de los sexmeros, representantes de las divisiones administrativas en las que se organiza el concejo- "con los seysmeros e procuradores de la dicha villa e su tierra", "con pieca asaz buenos omnes seysmeros"; "con los seysmeros de los quartos e de los lugares de la Sierra". Por contraste, en la segunda mitad de la centuria, y especialmente a partir de la década de 1460 , se torna visible una transformación en el registro de estos repartos ya que por un lado, comienza a dejarse una anotación más detallada de los pecheros que participan en estos procesos; al mismo tiempo que es palpable la mayor importancia de los concejos de la tierra -que para ese entonces alcanzaban el número de catorce- como instancias de representación. ${ }^{16}$ A la participación permanente de sus enviados en las derramas- sólo excepcionalmente se menciona la ausencia de los representantes de algún concejo-, ${ }^{17}$ se corresponde un compromiso más intenso en la elevación de peticiones al conde, en las disputas entre distintos concejos de la tierra o la elaboración de ordenanzas propias de los concejos aldeanos. ${ }^{18}$

Pese a tratarse de un concejo de dimensiones limitadas cuyo núcleo urbano tiene un carácter rural marcado, aspecto que constatamos en el tipo de actividades que desarrollan los productores de la villa; es necesario establecer una comparación entre algunos aspectos ligados a la representación política de la villa y de la tierra, así como en cuanto al tipo de acumulación económica desarrollada por los sectores enriquecidos del estamento pechero.

Un primer aspecto a destacar en este sentido tiene que ver con la permanencia en los cargos. Al igual que en las procuradurías de la villa, en la documentación concejil algunos nombres de los procuradores de los concejos rurales se reiteran -aunque no con la misma frecuencia que se constata a nivel urbano-. Entre algunos de ellos podemos mencionar a Juan de la Rueda, procurador del concejo de Navalescorial, quien en 1467 cumple tanto esta función en un repartimiento como la de "procurador de los fechos de la tierra" (Del Ser Quijano, 2016, 14, 22). Su representación del concejo de Navalescurial se mantiene a lo largo de toda la década de 1470 -en 1470, 1472, 1473, 1474, 1476, 1477 y 1478 (Del Ser Quijano, 2016, 51, 62, 73, 79, 91, 97, 102, 105, 106, 107, 108). Similar es el caso de otro vecino de Navalescurial, Pedro Gómez del Barrio, quien también es procurador de la tierra en 1467 y se desempeña como representante del concejo local en los repartimientos de 1472, 1473, 1475 (Del Ser Quijano, 2016, 22, 61, 63, 74, 84, 87, 88), en esta última ocasión junto a su hijo Ferrand Gómez.

Por parte del concejo de Hoyorredondo se destaca Pedro González de los Robres, procurador en 1468 y representante del lugar en 1471 y en 1477 (Del Ser Quijano, 2016, 31, 56, 60, 101, 102); ${ }^{19}$ y por Zapardiel, Juan Sánchez Barroso quien es procurador del concejo aldeano en 1470 1471, 1474, 1475 y 1478 (Del Ser Quijano, 2016, 47, 52, 56, 79, 82, 84, 88, 108).

En otros concejos rurales la reiteración de los nombres enviados a los repartimientos constituye una excepción. En este sentido, la rotación de los representantes de la tierra parece ser un rasgo habitual que comienza a debilitarse en la segunda mitad del siglo XV, particularmente en algunos de los concejos más importantes. Por otro lado, si en el caso de los procuradores de la villa parece evidente que son los sectores prominentes quienes ocupan dichos cargos, entre aquellos que confeccionan los padrones se busca sostener una representación equitativa; en 1469 las autoridades de Piedrahíta piden a los concejos de las aldeas que nombren a "tres o quatro buenos onbres de los más rricos e de los medianos e de los más pobres" (Del Ser Quijano, 2016, 44: 90); disposición que se repite en el mandado a los concejos de San Martín del Pimpollar y de Navalperal, a raíz de una disputa por la forma del cálculo de las pecherías: "que tomen seis buenos onbres, 
dos de los rricos e los otros dos de los medianos e los otros dos de los pobres, e lo que ellos estimaren que vale e lo que ellos dixieren que vale por eso pague...” (Del Ser Quijano, 2016, 83: 150).

En relación a la acumulación patrimonial llevada adelante por los sectores del común, el análisis de los libros de finanzas del concejo de Piedrahita evidencia una menor participación de los pecheros de la tierra en el arriendo de rentas concejiles y bienes de propios. No obstante, sí se deja registro de una serie de ventas de toros al concejo por sumas significativas por parte de algunos vecinos de las aldeas, quienes también se desempeñan como representantes de los concejos rurales. El ya mencionado Juan de la Rueda es un ejemplo, ${ }^{20}$ como también Alfonso Ruiz del lugar del Pimpollar. ${ }^{21}$

Del mismo modo, el concejo de la villa compra toros en diversas oportunidades a los vecinos de Navarredonda: Juan Redondo, Alonso Martínez de Barajas, Alfonso García de los Pinos, son algunos ejemplos. ${ }^{22}$ Estos pecheros de la tierra no solamente aparecen en la documentación concejil actuando en representación del lugar en los repartimientos que se resuelven en el ayuntamiento, sino que su actividad es intensa también en el concejo rural. Navarredonda es el único concejo de aldea del que se conserva el registro de las disposiciones locales, como traspasos y compra-venta de tierras entre otros. El estudio de estas fuentes nos permite constatar que estas figuras forman parte de familias que participan de forma activa en la vida política aldeana, desempeñándose como alcaldes, jurados, escribanos, testigos, sacristanes.

Veamos de manera breve el caso de Juan Sánchez Redondo. La primera vez que se lo menciona es en 1467 frente a la demanda que el alcalde y procurador Alonso Fernández de la Calleja le realiza en nombre del concejo por el cercamiento de una tierra que viola el régimen de alternancia de cultivo del lugar:

"e puso por demanda a Juan Sánchez Rredondo en que el dicho Juan Sánchez guardase el prado que dicen del Fortigal Mayor, non lo podiendo fazer de derecho, dos años que el concejo avía de posesión en el dicho prado, e que el dicho Juan Rredondo non á por qué guardar el dicho pra[do]”. (Del Ser Quijano, 1998, 26: 203).

A lo largo de las anotaciones de los acuerdos del concejo, volverá a aparecer intercambiando tierras. Las transacciones efectuadas con el concejo, en el que también se desempeña como representante en el repartimiento de 1470 (Del Ser Quijano, 2016, 49) y como alcalde en 1478 (Del Ser Quijano, 1998, 130: 224), apuntan al reagrupamiento de sus posesiones en el área del Fortigal donde acrecienta su patrimonio particular (Del Ser Quijano, 1998, 74: 211; 92: 216; 96:216; 108: 218).

En esta línea, el seguimiento de la actuación patrimonial de algunos de estos sujetos realizado por Laura da Graca (2003-2006; 2015), permite advertir la importancia de la mediación del concejo rural en el desarrollo de algunas de estas estrategias. El estrato enriquecido de la aldea concentra y cierra sus tenencias a partir de la capacidad de negociación que le brinda el acceso al poder político local. Estos arreglos alteran los usos colectivos y merman el pasto común en detrimento del acceso a la tierra de los demás vecinos. En esta dirección, su actuación política a nivel comunitario no es incompatible con la apropiación del espacio comunal, por el contrario esta posición preeminente habilita el desarrollo de dichas prácticas. ${ }^{23}$

\section{Algunas Reflexiones Finales}

El estudio empírico del concejo de Piedrahíta en el siglo XV nos ha permitido profundizar en la caracterización de las estrategias y prácticas de los segmentos superiores de los pecheros.

Una primera cuestión relevante es la emergencia y consolidación en un ámbito señorializado de un sector de los dominados que experimenta un proceso de acumulación patrimonial a partir de actividades ligadas de forma estrecha a la reproducción de la propia relación de explotación feudal. Al igual que un sector de los privilegiados, en el concejo de Piedrahíta un segmento destacado de tributarios participa activamente del arriendo de rentas y de bienes de propios, de lo cual se derivan ingentes beneficios.

Este tipo de acumulación se presenta fundamentalmente entre los pecheros con residencia en la villa, aunque como hemos visto esta distinción en un concejo de dimensiones limitadas y con un carácter rural 
marcado, puede resultar arbitraria. La participación de los sectores aldeanos en estas actividades pareciera significativamente menor, destacándose entre ellos quienes encuentran en la actividad agropecuaria su principal fuente de fortuna.

Sin embargo, existen puntos de contacto entre estos perfiles que conforman la elite de los tributarios. En primer lugar, frente a las interpretaciones clásicas que hemos reseñado al comienzo de esta contribución, enfatizamos la necesidad de revisar críticamente la existencia de una lógica estrictamente económica. Las vinculaciones personales con los sectores de poder urbanos, las relaciones familiares y el acceso a los cargos políticos concejiles, tanto a nivel urbano como en los concejos aldeanos, son elementos claves -y quizás objetivos en sí mismos- para la consolidación y proyección de estos sectores. Esta cuestión nos lleva a matizar el marcado contraste que ha establecido la historiografía hispanista entre los agentes de origen campesino que se guían por una lógica exclusivamente económica y la lógica estamental propia de los sectores feudales, dentro de los cuales queda subsumida la oligarquía de caballeros. Las llamadas elites de las comunidades se distinguen por la heterogeneidad de recursos de los que disponen y las múltiples estrategias que desarrollan para fortalecer sus posiciones (Furió, 2007; Pascua Etchegaray, 2007).

Por último, es preciso señalar que las prácticas de estas elites tienen una incidencia efectiva en la degradación de las condiciones materiales del resto de los tributarios, ya sea por el papel destacado que cumplen el arriendo de tributos, o como hemos advertido en el caso de Navarredonda, por la apropiación de espacios concejiles y la consiguiente transformación del régimen de la tierra. En este sentido, el compromiso de estas minorías en la gestión de la relación de explotación no solo reproduce el orden dominante, sino que contradictoriamente lo amenaza. Pero esto amerita un futuro trabajo.

\section{Bibliografía}

Aparisi Romero, F. (2013). "Las elites rurales en la edad media como objeto de estudio. Un recorrido historiográfico”. Historia. Instituciones. Documentos, 40, pp. 11-34. Disponible en https://dialnet.unirioja.es/servlet/revista?c odigo $=1631$

Asenjo González, M. (1984). "Labradores ricos: Nacimiento de una oligarquía rural en la Segovia del siglo XV”. En la España Medieval, 4, pp. 63-86.

Astarita, C. (2005). Del feudalismo al capitalismo. Cambio social y político en Castilla y Europa Occidental. 1250-1520, Valencia: PUV.

Borrero Fernández, M. (2008) “Elites rurales y mercado en la Andalucía bajomedieval”. En A. Furió; F. García- Oliver (eds.). Pautes de consum i nivell de vida al mundo rural medieval. Valencia: Universidad de Valencia, disponible en https://www.uv.es/consum/borrero.pdf

Borrero Fernández, M. (2015). "Las elites rurales en la Andalucía bajomedieval". Archivo hispalense: Revista histórica, literaria y artística, 297-299, pp-235-262.

Calderón Ortega, J. M. (2005). El ducado de Alba. La evolución histórica, el Gobierno y la Hacienda de un Estado señorial (siglos XIV-XVI). Madrid: Dykinson.

Calderón Ortega, J. M. (1994). "Los riesgos de la política en el siglo XV: la prisión del conde de Alba (1448-1454)”. Historia. Instituciones. Documentos, 21, pp. 41-62.

Clemente Ramos, J. (2011). "Elites rurales en Extremadura a finales de la Edad Media. El mayoral Juan Rubio (1499)". Studia Historica. Historia Medieval, 29, pp. 229-246.

Clemente Ramos, J. (2004). “Las Ordenanzas de Mengabril de 1548”. Revista de Estudios Extremeños, LX/ II, pp. 597-650.

Da Graca, L. (2015). “Concejos rurales y aspectos de gestión en la tierra de Piedrahíta (siglo XV)”. En la España Medieval, 38, pp. 195-230.

Da Graca, L. (2003-2006). “Intercambio de tierras y otras prácticas agrarias en concejos castellanos (siglo XV)”. Edad Media, 14, pp. 111-144. 
De Santos Canalejo, E. (1986). "Piedrahíta, su Comunidad de Villa y Tierra y los duques de Alba en el siglo XV”. En la España Medieval, 5, pp. 1141-1174.

Diago Hernando, M. (1990). “El 'común de los pecheros' de Soria en el siglo XV y primera mitad del XVI”. Hispania, 174, pp. 39-91.

Dobb, M. (1975). Estudios sobre el desarrollo del capitalismo, Buenos Aires: Siglo XXI.

Domínguez de la Concha, A. (2016). "Ascenso y declive de la élite rural de la Puebla de Guadalupe (Cáceres) durante los siglos XIV y XV”. Studia historica. Historia Medieval, 34, pp. 271-295.

Dyer, Ch. (1984). “Changes in the size of peasant holdings in some west midland villages 1400-1540”. En R. Smith (ed.). Land, kinship and life-cycle, Cambridge: University Press, pp 277-294.

Dyer, Ch. (1998). "Los orígenes del capitalismo en la Inglaterra medieval". Broccar. Cuadernos de investigación histórica, 22, pp. 7-20.

Feller, L. (2003). “L'historiographie des élites rurales dans le haut Moyen Âge. Emergence d'un problème?”. En $L$ 'bistoriographie des élites dans le haut moyen âge. (Actes du colloque, Université Marne-la-Vallée 28-29 novembre 2003), pp. 5-17. disponible en http://lamop.univ-paris1.fr/IMG/pdf/feller.pdf

Feller, L. (2015). Campesinos y señores en la Edad Media. Valencia: Universidad de Valencia.

Furió, A. (2007). "Las elites rurales en la Europa medieval y moderna. Una aproximación de conjunto". En A. Rodríguez (coord.) En torno a la obra de Reyna Pastor. El lugar del campesinado. Valencia: PUV, pp. 391-421.

Guinot Rodríguez, E. (2010). “Oligarquías y clientelismo en las comunidades rurales del sur de la Corona de Aragón (Siglos XIII-XV)”. Hispania. Revista Española de Historia, 235, pp. 409-430.

Hilton, R. (1974). The Economic Development of some Lecestershire Estates in the 14th and 15th Centuries. Oxford: Oxford University Press.

Hilton, R. (1988). Conflicto de clases y crisis del feudalismo. Barcelona: Crítica.

Jara Fuente, J. A. (2002). "Posiciones de clase y sistemas de poder: vinculaciones y contradicciones en la construcción del Común de pecheros en la baja Edad Media”. En J. I. De la Iglesia Duarte; J. L. Martín Rodríguez (coord.) Los espacios de poder en la ciudad medieval: XII Semana de estudios Medievales. Logroño: IER, pp. 511-532.

Jara Fuente, J.A. (2002-2003), “"Que memoria de onbre non es en contrario": usurpación de tierras y manipulación del pasado en la Castilla urbana del siglo XV", Studia Historica. Historia medieval, núm. 20-21, 2002-2003, pp.73-103.

Lenin, V. I. (1957). Cap. II: “Descomposición del campesinado". En El desarrollo del capitalismo en Rusia. Obras Completas, Tomo III. Buenos Aires: Ed. Cartago, pp. 61-185.

Luchía, C. (2019). "Regir el concejo, servir al señor: los regidores del concejo de Piedrahíta en el siglo XV”. En la España medieval, 42, (En prensa).

Luchía, C. (2016). "Regidores en conflicto: pertenencia estamental, trayectorias individuales y estrategias de poder de las elites regimentales castellanas en el siglo XV”. Magallánica, 3/5, pp. 123-148.

Luis Lopez, C. (1987). La Comunidad de villa y tierra de Piedrahita en el tránsito de la Edad Media a la Moderna. Ávila: Ediciones "Gran Duque de Alba".

Menant, F. y Jessenne, J.-P. (eds.). (2007). Les Elites Rurales dans l'Éurope médiévale et moderne, Actes des XXVII Journées Internationales d'Histoire de l'Abbaye de Flaran 9, 10, 11 septembre 2005. Tolouse : Presses Universitaires du Mirail.

Monsalvo Antón, J. M. (1989). “La participación política de los pecheros en los municipios castellanos de la baja Edad Media. Aspectos organizativos”. Studia Historica. Historia Medieval, 7, pp. 37-94.

Monsalvo Antón, J. M. (1997). "Las dos escalas de la señorialización nobiliaria al sur del Duero: concejos de villa-ytierra frente a la señorialización "menor". (Estudio a partir de casos del sector occidental: señoríos abulenses y salmantinos)". Revista d'historia medieval, 8, pp. 275-338. Disponible en https://dialnet.unirioja.es/servlet/art iculo? codigo $=228782$

Monsalvo Antón, J. M. (2004). “Aspectos de las culturas políticas de los caballeros y pecheros en Salamanca y Ciudad Rodrigo a mediados del siglo XV. Violencias rurales y debates sobre el poder en los concejos”. En M. I. Alfonso 
Antón; J. Escalona Monge; G. Martín, (Coords.) Lucha política; condena y legitimación en la España medieval, Annexes des Cahiers de Linguistique et de civilisation hispaniques medievales, 16,pp. 237-396.

Monsalvo Antón, J. M. (2005-2006). “Percepciones de los pecheros medievales sobre usurpaciones de términos rurales y aprovechamientos comunitarios en los concejos salmantinos y abulenses”. Edad Media, 7, pp. 37-74.

Monsalvo Antón, J. M. (2011b). “Ideario sociopolítico y valores estamentales de los pecheros abulenses y salmantinos (ss. XIII-XV)”. Hispania: Revista española de historia, 71/ 238, p. 325-362.

Moreno Núñez, J. I. (2007). “Los señoríos de Navamorcuende, Cardiel y Villatoro, bienes vinculados. La quiebra del orden sucesorio y el mayorazgo de 1449”. Documenta \& Instrumenta, 5, pp. 99-127.

Moreno Núñez, J. I. (1992). Avila y su tierra en la baja Edad Media (siglos XIII-XV). Valladolid: Junta de Castilla y León.

Oliva Herrer, H. R. (2008). “Campesinos ricos, mercado y crecimiento económico en Castilla en el siglo XV”. En A. Furió; F. García- Oliver (eds.) Pautes de consum i nivell de vida al mundo rural medieval. Valencia: Universidad de Valencia, disponible en https://www.uv.es/consum/oliva.pdf

Pascua Echegaray, E (2007). “Las otras comunidades: Pastores y ganaderos en la Castilla Medieval”. En A. Rodríguez (coord.) En torno a la obra de Reyna Pastor. El lugar del campesinado. Valencia: PUV, pp. 209-238.

Sánchez Benito, J. M. (2008). "Estructura social de un pueblo de Castilla en época de los Reyes Católicos; Fuentes, aldea de Cuenca”. En la España medieval, 31, pp. 97-122.

\section{Fuentes}

Álvarez Fernández, M. (2011). Las finanzas de un concejo castellano: Piedrahita, Siglos XV-XVI. Estudio y documentos, Vol. VII (1474-1480).

Beltrán Suárez, S. (2011). Las finanzas de un concejo castellano: Piedrahita, Siglos XV-XVI. Estudio y documentos, Vol. VI (1467-1473). Ávila: Ediciones de la Institución "Gran Duque de Alba”.

Calleja Puerta, M. (2010). Las finanzas de un concejo castellano: Piedrahíta, Siglos XV-XVI. Estudio y documentos, Vol. I (1413-1433). Ávila. Ediciones de la Institución “Gran Duque de Alba”.

Del Ser Quijano, G. (1998), Documentación Medieval en Archivos Municipales Abulenses (Aldeavieja, Avellaneda, Bonilla de la Sierra, Burgohondo, Hoyos del Espino, Madrigal de las Altas Torres, Navarredonda de Gredos, Riofrio, Santa Cruz de Pinares y El Tiemblo). Ávila: Ediciones de la Institución "Gran Duque de Alba".

Del Ser Quijano, G. (2010). Documentación medieval de Piedrabita. Estudio, edición crítica e indices, vol. II (1448-1460). Ávila: Ediciones de la Institución "Gran Duque de Alba”.

Del Ser Quijano, G. (2011). Las finanzas de un concejo castellano: Piedrabita, siglos XV-XVI. Estudio y documentos, vol. II (1434-1444). Ávila: Ediciones de la Institución "Gran Duque de Alba".

Del Ser Quijano, G. (2016). Documentación medieval de Piedrabita. Estudio, edición critica e indices, vol. IV (1466-1480). Ávila: Ediciones de la Institución "Gran Duque de Alba".

Luis López, C. (2007). Documentación medieval de Piedrahita: estudio, edición critica e indices, vol. I (1372-1447). Ávila: Ediciones de la Institución "Gran Duque de Alba".

Luis López, C. (2011). Las finanzas de un concejo castellano: Piedrahita, siglos XV-XVI. Estudio y documentos, vol. III (1445-1452). Ávila: Ediciones de la Institución "Gran Duque de Alba".

Luis López, C (2012). Documentación medieval de Piedrahíta: estudio, edición crítica e índices, vol. III (1461-1465). Ávila: Ediciones de la Institución "Gran Duque de Alba".

Luis López, C. (2016). Documentación medieval de Piedrabita: estudio, edición crítica e indices, vol. V (1481-1493). Ávila: Ediciones de la Institución "Gran Duque de Alba".

Monsalvo Antón, J. M. (2011a). Las finanzas de un concejo castellano: Piedrahita, siglos XV-XVI. Estudio y documentos, vol. IV (1453-1461). Ávila: Ediciones de la Institución "Gran Duque de Alba".

Tena García, M. S. (2011). Las finanzas de un concejo castellano: Piedrahita, siglos XV-XVI. Estudio y documentos, vol. V (1462-1466). Ávila: Ediciones de la Institución "Gran Duque de Alba”. 


\section{Notas}

1 Inicialmente, los territorios son detraídos del concejo abulense a mediados del siglo XIII por el rey Alfonso X, en favor de su hermano el infante don Felipe, pero a comienzos de la centuria siguiente retornan al realengo hasta su constitución como el primer señorío nobiliario de Ávila y su entrega a García Álvarez de Toledo en 1369 (Luis López, 1987).

2 Esto ha sido planteado por José María Monsalvo Antón, quien destaca que, pese a las modificaciones que significa el proceso de señorialización, no se anula la personalidad jurídica de los concejos (1997: 323).

3 El concejo de Piedrahíta tiene una extensión de $66399 \mathrm{~km}$. Es un concejo considerado mediano en relación a la totalidad de la región concejil y el segundo en importancia del territorio abulense. (Luis López, 1987).

4 Estos rasgos han sido señalados por Corina Luchía quien establece una comparativa con lo observado en el concejo de realengo de Ávila donde el ausentismo de los regidores en el siglo XV es una constante y donde se verifica una mayor diferenciación entre las tareas políticas y las de gestión (Luchía, 2016: 164).

5 Desde otra perspectiva, el apoyo de la gestión concejil en el estamento pechero ha sido interpretado para el caso de Piedrahíta como un rasgo propio del perfil político de la oligarquía urbana de la villa que presentaría un desinterés por la rutina burocrática delegando tareas de gestión en miembros provenientes de los subalternos. (Da Graca, 2015: 211)

6 Hasta inicios del siglo XVI cuando pasará a ser elegido por la justicia y regidores de Piedrahíta. (Luis López, 1987: 175).

7 También en 1459 es presentado como fiador del carnicero Juan García, lo que nos habla de su holgada situación patrimonial. (Del Ser Quijano, 2010, 148: 282).

8 No podemos aseverar con certeza que Alonso Fernández de los Caños sea el mismo personaje que el mencionado en la década de 1430 o bien que se trate de un familiar directo.

9 "Las molestias que se toma Lope García ilustran la posición del mayordomo, tratado a la vez como subordinado incondicional y epicentro de la vida concejil (...) La exclusión del mayordomo de ciertos asuntos del concejo define también el perfil del oficial que más directamente encarna el nexo entre el concejo urbano y las aldeas" (Da Graca, 2015: 203).

10 En tanto que su yerno Ferrand toma por un año el riego de la dehesa concejil de los Arroyos por 400 maravedís (Del Ser Quijano, 2011, 140).

11 También se destaca la figura de Juan de los Caños, yerno de Alonso, quien en 1477 escribe el interrogatorio para tomar una pesquisa en 1477, recibe 330 maravedís por ir a buscar 8 carretas a San Helizes y es procurador en 1485 y en 1491 (Álvarez Fernández, 2011, 91; Del Ser Quijano, 2016, 102; Luis López, 2016, 7, 11, 66).

12 También en 1472 el mayordomo "dio por libramiento del dicho concejo a Lope de la Reyna e a Diego Sánchez Sastre quatrocientos maravedís, que los mandaron dar porque abaxaron el pescado al tiempo que se obligavan los pescadores" (Beltrán Suárez, 2011: 164).

13 Ese mismo año su hermano Bartolomé Sánchez Sastre también actúa como testigo (Luis López, 2016, 33), aunque no parece gozar de la misma relevancia.

14 Los fieles de Piedrahíta, al igual que en otros concejos, se ocupaban de la vigilancia del comercio de la villa y de velar por el cumplimiento de las ordenanzas respecto del abastecimiento interior sobre precios, pesas, medidas y varas. La disputa en torno a estos oficios probablemente se encuentre vinculada a los elevados ingresos que conllevan ya que accedían a una parte significativa de las penas que imponían por el incumplimiento de las normas. Esto queda reflejado en el propio reclamo: "que quando algunos fieles o alguazil non usaren del oficio derechamente, syn requerir a vuestra merced, la justicia y rregidores puedan poner otro o otros en sus lugares en los dichos oficios, e que non quiera dar albalaes a personas de fuera para madera de los dichos pinares, para que se saque fuera de vuestra tierra” (Luis López, 2012, 83: 125-126).

15 Espacio heterogéneo, el alfoz sobre el que ejerce jurisdicción la villa se divide en dos regiones principales: los Llanos, donde primaba la agricultura de cereales y el cultivo de huertas, y la Sierra, área de riqueza ganadera y forestal donde se encontraban los concejos rurales más importantes. (Santos Canalejo, 1986).

16 Los concejos rurales -que comprenden varias aldeas- son Navaescurial, Aldehuela, Santiago, Ho- yorredondo, Horcajo, Zapardiel, Navalperal, Navacepeda, Hoyos y Hoyos, Navarredonda, San Martín del Pimpollar, San Martín de la Vega, La Garganta del Villar y San Miguel de Corneja.

17 En el reparto del pedido ordinario solicitado por el señor en agosto de 1469 no asiste el procurador de Navarredonda ni el del concejo de la Vega (Del Ser Quijano, 2016, 39: 84). En 1471 quienes no asisten al reparto del pedido son los representantes de los concejos del Forcajo, Navalperal, Navacepeda y Navarredonda (Del Ser Quijano, 2016, 60: 111).

18 "A partir de 1468 se inicia un declive en la importancia de estas agrupaciones territoriales como forma de representación de la tierra, incluso a efectos fiscales, en beneficio de los concejos. Pierden entonces los sexmeros la exclusividad de representación de su comarca, compartiéndola con los procuradores de los distintos concejos, de tal forma que después de 1469 ya no figuran como representantes de sus comarcas ante el concejo de la villa de Piedrahíta, siendo cada vez más pujante la representación de los concejos de la tierra." (Luis López, 1987: 161). 
19 También sobresale la figura de Pedro García, quien participa de los repartos de 1469, 1470, 1471 y 1472 (Del Ser Quijano, 2016, 39, 43, 56, 61, 63).

20 Juan de la Rueda vende un toro al concejo por 990 maravedís (Tena García, 2011: 208).

21 Alfonso Ruiz del lugar del Pimpollar vende en 1460 un toro al concejo por 875 maravedís (Monsalvo Antón, 2011a: 174) y otro en 1463 por 1100 maravedís (Tena García, 2011: 126).

22 Alfonso García de Los Pinos vende un toro en 1462 por 780 maravedís (Tena García, 2011:55); Alfonso Martínez de Barajas vende dos toros en 1457, un toro tres años más tarde (Monsalvo Antón, 2011a, 101, 104, 173) y actúa en representación del lugar en un repartimiento en 1473 (Del Ser Quijano, 2016,73). Semejante es el caso de Juan Redondo quien también vende toros al concejo en 1457 (Monsalvo Antón, 2011a: 104) y representa al concejo de Navarredonda en un repartimiento en 1470 (Del Ser Quijano, 2016, 49).

23 Pese a mantenerse las asambleas como órganos de gobierno en los concejos de la tierra, parece presentarse una evolución en la delegación del poder en unos pocos miembros de la aldea, tal como se observa en las ordenanzas de Navarredonda de la Sierra de 1458, confirmadas al año siguiente por el señor: "Mas ordenaron que de cada un año que tengan cargo de los fechos del concejo seis onbres buenos con los alcaldes e que sean juramentado. E el concejo, estando a canpana rrepicada, les dio e da poder conplido para que todas las cosas que ellos fizieren que las da el concejo por firmes e valederas" (Del Ser Quijano, 2010, 142: 174). 